\title{
DOUTRINA
}

\section{O NOVO PAPEL DO ESTADO NA ECONOMIA*}

\section{DIOGO DE FIGUEIREdO MOREIRA NeTO}

I - Introdução; II - Premissas sobre o estado em transformação; III - O papel do estado na economia nos modelos dominantes de estado moderno; IV - Características relevantes da transição do estado moderno para o estado pós-moderno; $V-O$ novo papel do estado na economia no estado pós-moderno; VI - Apreciação do impacto das mudanças sobre os modelos de constituição; VII - O problema da constitucionalização das mudanças no Brasil; VIII - Outras tendências em curso e conclusões

\section{$I$ - Introdução}

O tema se insere de pleno na problemática das profundas e céleres mudanças que estão em curso desde o término da Segunda Guerra Mundial e, por isso, não prescinde de uma apreciação, multidisciplinar, ainda que sucinta, do cenário em que ocorrem essas transformações, uma vez que um enfoque sobre o novo papel do Estado na economia parte, necessariamente, das próprias alterações observadas na sociedade.

O método da exposição partirá, portanto, de uma reflexão sobre algumas premissas relativas ao Estado em transformação, para prosseguir com um exame retrospectivo do papel do Estado na economia nos modelos dominantes do Estado moderno. Passará daí à análise da transição do Estado moderno para o Estado pós-moderno, onde serão apresentadas certas características das mutações em curso, para chegar ao conceito do que seja o novo papel do Estado na economia no Estado pós-moderno. Finalmente, oferece-se uma apreciação do impacto dessas transformações sobre os modelos de Constituição e, destacadamente, o problema da constitucionalização das

* Apontamentos de palestra preparada para o Seminário de aberturá do Programa de Curso de Pós-graduação em Direito do Estado e Economia da FGV - Direito - Rio de Janeiro, em julho de 2005. 
mudanças no Brasil, encerrando-se o estudo com a indicação de algumas outras tendências esboçadas com repercussão econômica e breves conclusões.

\section{II - Premissas sobre o estado em transformação}

Três reflexões são oferecidas como premissas para este trabalho: $1^{\circ}$ ponto

A globalização tem um profundo impacto na economia, mas, distintamente do que se possa superficialmente imaginar, ela não conduz nem a uma homogeneização radical nem a uma homogeneização universal das sociedades e dos países, pois o processo apresentará sempre resultados diferentes segundo os contextos locais.

A respeito, recorde-se o paradoxo de SAMUEL HUNTINGTON ${ }^{\prime}$, com seus neologismos explicativos, a globalization e a "glocalization", que exprimem movimentos simultaneamente centrípetos e centrífugos.

\section{$2^{\circ}$ ponto}

O Estado se transforma, mas não perece. Ao contrário, se expande, se torna mais complexo e até se desburocratiza, na medida em que a sociedade ascende como coprotagonista da política e se vai apresentando como uma organização policêntrica, paralela e colaboradora em suas atividades.

A respeito, lembre-se a consagrada visão de MANUEL CASTELLS ${ }^{2}$ sobre a sociedade e o Estado em rede.

\section{$3^{\circ}$ ponto.}

O Estado, como expressão da modernidade, difundiu-se planetariamente como modelo de organização do poder baseado no binômio: razão - indivíduo.

Assim, tudo seria seguro no reino da razão e o locus do indivíduo, como homem civilizado, não poderia ser outro que o Estado, postado como ápice do desenvolvimento do racionalismo na política, e nunca na sociedade, que como cadinho de interesses e de emoções, careceria da segurança da condução e da tutela do Estado.

III - O papel do estado na economia nos modelos dominantes de estado moderno

O modelo de Estado moderno evoluiu de um protótipo personalizado e absolutista (séculos XVI e XVII), caracterizado pelo poder de direção ilimitado do

1 SAMUEL HUNTINGTCN, Le choc des civilizations, Paris, O. Jacob, 1966.

2 MANUEL CASTELLS, A Sociedade em Rede - A Era da Informaçāo: Economia, Sociedade e Cultura. S. Paulo, Editora Paz e Terra, 1999. 
monarca, para configurações mais avançadas, como a dos tipos de Estados legali$z a d o s^{3}$ e contidos que se seguiram, sob a égide do Estado de Direito.

Com a evolução, houve uma infusão de valores humanísticos que plasmou o modelo liberal (séculos XVIII e parte do XIX), que, por sua vez, com a Revolução Industrial, foi substituído por dois modelos interventivos: o do bem-estar social (final do século XIX e a maior parte do século XX) e o socialista (a maior parte do século $\mathrm{XX}$ ).

Pode-se afirmar, portanto, que esses dois modelos novecentistas - o do bemestar social e o socialista - mantiveram-se hegemônicos praticamente até o último quartel do século passado, quando começaram a se afirmar as características gerais de uma nova configuração contemporânea, in fieri que, por falta de uma designação consensualizada, tem sido identificada apenas como Estado pós-moderno ${ }^{4}$, como adiante se discorrerá.

Nesses três modelos históricos considerados, o papel do Estado na economia variou da extrema abstenção (liberalismo) à extrema intervenção (socialismo real), com inúmeras variantes históricas intermediárias entre as duas posturas radicais.

O certo é que o movimento da primeira industrialização, no período que vai do fim do século XIX ao final do segundo decênio do século XX, marcou o ocaso da conformação páleo-liberal passiva do Estado na economia, sintetizada no laissez faire, laissez passer, e que passou a ser reorientada pelo surgimento de uma conformação ativa, inicialmente caracterizada por quatro aspectos sublinhados por SABINO CASSESE ${ }^{5}$ em sua obra La nuova costituzione economica: a diferenciação legislativa, a política de obras públicas, as empresas estatais e a previdência social:

1 - a diferenciação legislativa - com a instituição de áreas geográficas diferenciadas, de processos de administração diferenciados e de órgãos diferenciados para canalizar ação do Estado;

2 - a política de obras públicas - para constituir uma infraestrutura pública voltada ao crescimento econômico;

3 - as empresas estatais - para suprir a falta de investimentos privados em setores específicos e

4 - a previdência social - ao inaugurar uma relação social tripolar: Estado-trabalhador-empresa.

3 EDUARDO GARCÍA DE ENTERRÍA, diz em seu primoroso Democracia, Jueces y Control de a Administración que "Es sobre esta técnica de la legalización del poder sobre la que se forma todo el Derecho Público moderno, desde las turbulencias iniciales de la Revolución." (Madri, Civitas, 5' edição, 2000, p 40).

4 JACQUES CHEVALIER, LÉtat post-modeme, Paris, LGDJ, 2003.

5 SABINO CASSESE, La nuova costituzione economica, Roma-Bari, Editori Laterza, $4^{`}$ edição, 1997. 
Estava assentado o modelo de Estado interventivo em seu tríplice aspecto distributivo, produtivo e providencial - que ainda mais se reforçaria até atingir o seu auge na metade do século passado: primeiro, com a grande crise que abalou o mercado (o crack da Bolsa de Nova Iorque) e, depois, com as sucessivas guerras mundiais que o reforçariam política e militarmente (agregando os conceitos de mobilização e de segurança nacionais).

Este modelo, já no início do século XX, desdobrou-se em duas modalidades históricas: a do Estado do bem estar social, em que a tônica comum, da intervenção na economia, seria moderada, pois seu objetivo era o de superar a igualdade formal do liberalismo e alcançar a igualdade material por meio da tributação e de políticas públicas assistenciais, e a do Estado socialista, em que a intervenção econômica (bem como a social) seria extremada, pois seu objetivo seria o de se substituir à própria sociedade na condução de seu destino.

Como se apreciará a seguir, ambos os modelos entraram em crise na segunda metade do século XX, pois, como explica SABINO CASSESE, "Se nos anos 30 estava difusa a idéia da falência do mercado, nos anos 60 se difunde a idéia da falência do Estado como regedor da economia". 6

Diante dessa dupla falência, evidenciada pela ineficiência crônica dos serviços públicos; pelo endividamento público intolerável; pela inflação perversa e irredutível; pelo belicismo dos governos, com suas corridas armamentistas; e pelo peso crescente dos tributos, as sociedades nacionais não tinham alternativa que partir para a reformulação dos dois modelos interventivos e, reivindicando então o seu protagonismo, desenvolver um modelo misto, temperando a organização e disciplina até então atingidas pelo Estado, com as potencialidades inesgotáveis de criatividade própria das sociedades livres.

\section{IV - Características relevantes da transição do estado moderno para o estado pós-moderno}

Com o impacto catastrófico das guerras mundiais provocadas pelos Estados vintecentistas - as duas "quentes" e a "fria", mas não menos letal - o mundo racionalista, que os suportava, entrava em crise, provocando uma transformação em que se destacam os seguintes fatores de transição, externos e internos.

Fatores externos:

1. explosão das comunicações

2. reavaliação da pessoa humana e emergência de seus direitos fundamentais como fundamento do Direito

3. democratização

4. globalização 
Fatores internos:

1. ineficiência do Estado moderno

2. custo excessivo do Estado moderno

Examinem-se, portanto, esses seis fatores, não necessariamente na ordem acima, como chave para o entendimento dos rumos da transição para o novo modelo contemporâneo.

\section{Explosão das comunicações}

A tecnologia das comunicações produz uma nova sociedade, a sociedade da informação - A Internet inicia em 1922 um papel totalmente novo nas relações humanas: é a "rede sem coração nem cabeça", um fenômeno alheio ao Estado e quase incontrolável, salvo se existissem instituições globais com esta capacidade. Esta sociedade não atua mais segundo os padrões tradicionais e a dinâmica das informações, em escala planetária, a torna mais atilada e demandante, o que faz obsoleto, que mais não seja apenas por este motivo, o Estado em suas versões modernas.

\section{Ineficiência das prestações estatais}

O racionalismo não foi, afinal, a resposta esperada aos reclamos das sociedades e as ideologias, tampouco responderam às promessas que apregoaram. $\mathrm{O}$ Estado totalitário, que se arrogava a pretensão de exercer a gestão estatal racionalizada e integrada sobre todos os indivíduos e sobre todos os processos sociais, fracassou em qualquer de suas versões. Do mesmo modo, o Estado-providência, que buscava conciliar racionalismo e democracia, prescindindo de ideologias para sustentá-lo, acabou por tornar os cidadãos acomodados e passivos e permitir que as suas empresas estatais, que se propunham a prestar serviços e oferecer bens abundantes e baratos atuando à margem do mercado, se deixassem contaminar pela burocracia e pela inércia, perseguindo finalidades corporativas próprias e perdendo lentamente a pouca eficiência que ainda poderiam manter na ausência de qualquer competição que as estimulasse. Por fim, nos Estados em desenvolvimento, esse processo de degradação ainda mais se agravava com a desvalorização das matérias primas, o endividamento, a inflação e a corrupção endêmica.

\section{Custo excessivo da máquina do Estado moderno}

O Estado moderno leva a marca do desperdício e quanto maior seu aparelho burocrático e mais centralizado, menos controlável. Na realidade, foi um Estado perdulário, em que o controle dos gastos públicos era apenas formal, consistindo na mera satisfação de procedimentos financeiro-orçamentários, sem que importassem os aspectos substantivos, como a economicidade e a legitimidade. Em consequiência os recursos captados por via impositiva jamais bastavam, de modo que esses Estados 
do déficit público acabaram se tornando, em sua grande maioria, Estados da voracidade fiscal, curiosamente até representados por ícones invocativos de animais predadores, e Estados do endividamento progressivo e da inflação, as novas pragas apocalípticas que deram o golpe de misericórdia no modelo de Estado moderno.

\section{Democratização}

Por outro lado, graças às comunicações e à elevação do nível educacional das sociedades, a democracia chegava à maioridade, exigindo novos processos de legitimação além do tradicional processo de representação política. O recuperado conceito de democracia substantiva passou a exigir visibilidade da ação estatal (transparência), participação cidadã, sempre que possível, e, sobretudo, a eficiência estatal nas prestações públicas a seu cargo.

\section{Globalização}

A economia da globalização é o grande motor das mudanças do Estado, conformando o grande mercado único planetário e a abertura econômica passa a ser condição de acesso a este mercado. As barreiras ao comércio começam a ser contestadas e combatidas, proliferando os acordos aduaneiros, as zonas de livre comércio e as uniões econômicas, promovendo-se a integração das economias por intercâmbios de toda ordem: financeiros, industriais, comerciais e mistos, envolvendo aspectos sociais e culturais. Por outro lado, ainda quanto aos intercâmbios, a desintermediação econômica vem acelerar e baratear as transações, que se beneficiam ainda da celeridade dos meios de comunicação disponíveis. Nesse novo cenário globalizado, passam a ser necessários novos mecanismos de regulação extra-estatais, que passam a conviver com os tradicionais mecanismos de regulação intra-estatais e, em especial, os mega fluxos de investimentos intercontinentais determinam o aparecimento das agências de risco. Por fim, as empresas globalizadas, as transnacionais e multinacionais, chegam a representar um terço da produção mundial de bens e serviços, nelas concentrando poder econômico em escala planetária que raros Estados podem emular.

\section{Reavaliação da pessoa humana e emergência dos seus direitos fundamentais como fundamento do Direito}

Nesse cenário, a pessoa humana vive uma ambigüidade. No lado positivo das comunicações e da globalização, afirma-se a dignidade do ser humano, proscreve-se o abuso de poder político, econômico e social sem proteção e reentroniza-se o homem como centro da vida social, individualmente e coletivamente considerado. No lado negativo das comunicações e da globalização, prosperam o crime organizado, as máfias internacionais, as formas mais fanáticas e violentas de terrorismo e multiplicam-se as migrações desordenadas, o que, em síntese, marca o sombrio advento da sociedade de risco, a que se referem os autores que cunharam a expressão: P. 
LAGADEC ${ }^{7}$ (la civilisation du risque), em 1981, e U. $\mathrm{BECK}^{8}$ (la societé du risque), em 1986.

Assim, se a legalidade havia sido o suporte do moderno Estado de Direito ${ }^{9}$, os direitos fundamentais passaram a ser o suporte pós-moderno de legitimidade do pós-moderno Estado Democrático de Direito.

A esses fatores, aqui expostos em relação não exaustiva, mas com a preocupação de compor um cenário compreensível da crise que levou à transição do Estado moderno para o modelo pós-moderno, agregam-se alguns aspectos corolários, porém dignos de nota:

1. A sociedade amadurece: torna-se pluralista, não aceita mais o dirigismo, demanda participação e não se conforma apenas com a os ritos da democracia formal como via de legitimação da ação pública.

2. A moeda deixa de ser entendida como um bem do Estado para ser considerada como um bem da sociedade, que lhe infunde valor com a produção de seus bens e serviços. Com isso, o Estado vê-se compelido a cada vez menos dispor politicamente da moeda para limitar-se apenas a geri-la administrativamente para assegurar sua confiabilidade e sua estabilidade.

3. Abre-se, com isso, um imenso espaço de crescimento da competitividade e da mobilidade financeira internacional, com seus aspectos positivos e negativos demandantes de institutos que os Estados não mais têm condições de desenvolver, salvo operando de forma associada e global.

O comércio internacional, que segue a mesma tendência com a ampliação da competição, altera, por sua vez, os sistemas de produção e de exportação de bens e de serviços, tornando inútil, na maioria dos países, quaisquer esforços do Estado para reverter situações comerciais adversas.

4. O progresso, enfim, deixa de ser assunto exclusivo dos Estados modernos e as sociedades começam a sentir necessidade de outras instituições, mais especializadas, mais sofisticadas, mais flexíveis, preferentemente autogovernadas e globalizadas para atender aos novos desafios.

Como se depreende, nesse quadro, as mutaçōes do Estado e do seu Direito seriam, como o foram, inevitáveis, preparando a rápida transição para o modelo de Estado pós-moderno.

\section{$V-O$ novo papel do estado na economia no estado pós-moderno}

As mudanças econômicas que ocorreram nos modelos modernos de Estado dominantes até a Segunda Guerra Mundial, para o atual modelo pós-moderno, ainda

7 P. LAGADEC. La civilisation du risque, Paris Ed. Du Seuil, 1981.

8 U. BECK. La societé du risque, Paris, Ed. Aubier, 1986.

9 EDUARDO GARCÍA DE ENTERRÍA, na obra mencionada, refere-se ao "Estado de Derecho" en el sentido (que era, por cierto, el de los autores clásicosalemanes más tes del XIX y XX) de un Estado con Derecho Administrativo pero sin derechos fundamentales." (ps. 47/48). 
em construção, foram condicionadas por duas idéias-força: a competição e a eficiência.

Observe-se, porém: não mais uma competição entre Estados, adscrita à eficiência bélica e à dominação de mercados coloniais, outrora tão importantes na era das grandes potências, mas, distintamente, uma competição entre sociedades, muito mais voltada à eficiência econômica, coadjuvada pela eficiência política da atuação estatal nas relações internas e externas, bilaterais e multilaterais, a eficiência administrativa, na execução das políticas públicas e, ainda, sob outro ângulo, até mesmo uma qualificada eficiência social, que consiste em eliminar a exclusão econômica e em resguardar e em promover a qualidade dos bens e serviços, sejam públicos ou privados.

Mas atingir competição e eficiência no plano interno, não mais depende apenas da ação dos Estados, mas, cada vez mais, do concerto de uma parceria franca com sociedades solidarizadas pela democracia e, ainda, no plano externo, tampouco depende da atuação de Estados isolados, só se logrando satisfatoriamente através de um concerto institucionalizado de Estados associados.

Essa nova acepção de eficiência passa a ser vital no processo de globalização, como um imperativo não só de desenvolvimento como de sobrevivência, em um mundo em que as demandas não podem deixar de ser atendidas a contento, seja pelas instituições públicas, seja pelas instituições privadas. Com efeito, as pessoas querem ter seus interesses satisfeitos, pouco importando quem deles se ocupe: se uma entidade privada ou governamental ou se uma entidade nacional, multinacional ou estrangeira. Com isso, o nacionalismo, como exacerbação desfigurada do patriotismo, deixa de ser uma avassaladora idéia-força, ou melhor, um mito, capaz de compensar a pobreza, o sacrifício e o subdesenvolvimento, para voltar a ser apenas mais uma referência entre outras, porém já não mais suficiente para justificar, como outrora, aquela habitual e passivamente tolerada ineficiência estatal, que, muito embora criticada, sempre acabava absorvida no contexto dominante da onímoda e indiscriminada subordinação do interesse privado ao público, como se fossem inconciliáveis; uma triste característica do Estado-nação, nos seus modelos interventivos ultrapassados.

Assim é que o novo desempenho do Estado na economia, sob a égide deste binômio - competição e eficiência - evolui do papel conformativo do mercado, próprio das regulamentações diretas e indiretas, e do papel substitutivo do mercado, próprio das intervenções concorrenciais e monopolísticas, para tornar-se (1) regulador do mercado, (2) alocador de recursos, (3) parceiro econômico e (4) fomentador econômico.

1. Como regulador do mercado, o Estado, especializando-se em seus diversos setores e segmentos, abandona a pura e exclusiva direção política dos processos econômicos para aliá-la com a direção técnica e socialmente concertada através de entes independentes, criados para desenvolver políticas econômicas legislativas, antes que meramente executivas. É o Estado regulativo, que pratica a light intervention, pró-mercado, desenvolvida pelos Estados Unidos da América como alternativa às formas de heavy intervention, antimercado, desenvolvidas na grande maioria dos modelos do bem-estar social europeus durante o século XX. 
2. Como alocador de recursos, o Estado desempenha duas funções distributivas: uma externa (ou política), através de políticas sociais voltadas aos segmentos assistidos, e outra, interna (ou administrativa), que se executa através dos orçamentos públicos, na distribuição dos meios financeiros entre entes e órgãos. É o Estado distributivo atuando em função alocativa, atividade que se distingue da função regulativa por quatro características: sua mutabilidade (anual), sua aleatoriedade (dependência de fatores financeiros disponíveis), seu tríplice formato das relações (quem paga, quem recolhe e quem distribui os recursos) e sua relação direta com o cidadão economicamente beneficiado.

3. Como parceiro econômico, o Estado, ao mesmo tempo em que supera suas próprias limitações financeiras, técnicas e empresariais, associando-se a parceiros privados, despe-se de prerrogativas anacrônicas que, a pretexto de protegerem os interesses públicos a seu cargo, na verdade atuam como fatores de afastamento do concurso espontâneo da sociedade e até de encarecimento dos bens e serviços que devem ser buscados no mercado para atender a suas próprias necessidades administrativas. Acresce que a importância do Estado parceiro vai além da ampliação de suas possibilidades pela associação com a iniciativa privada, pois a convocação dos entes da sociedade à colaboração é também, por si mesma, um extraordinário incentivo para o setor privado.

4. Por fim, é nesta referida atuação, de fomentador econômico que o Estado desempenha sua mais nobre função, despido de coercitividade, em vias de transformação para um modelo de Estado propulsivo, que se torna de forma crescente um impulsionador de iniciativas (fomento empresarial), promotor de oportunidades de trabalho (fomento laboral), incentivador de investimentos (fomento financeiro) e desbravador de novas alternativas econômicas (fomento científico-tecnológico).

\section{VI - Apreciação do impacto das mudanças sobre os modelos de constituição}

Por certo essas mudanças, que se cristalizam em novos institutos e em novas versões de antigos institutos, não são necessária e formalmente espelhadas em todos os textos constitucionais de Estados pós-modernos, ainda porque, a pós-modernidade vai depender muito mais de uma evolução constitucional permanentemente introduzida pelo legislador reformador e pelos tribunais constitucionais, e, na percepção de PETER HÄBERLE, até mesmo por obra do legislador ordinário, dos juízes, da doutrina e da praxe, o que denomina de um "processo público" próprio de "uma sociedade aberta de legisladores e intérpretes da Constituição". ${ }^{10}$

Muito concorre para a realização dessa "Constituição viva" a interpretação integrativa, adaptativa, criativa e permanente, a cargo das cortes constitucionais, produzindo o que se tem denominado de mutação constitucional sem alteração do texto.

10 PETER HÄBERLE, Introdução sobre a Constituição Alemā, in Le Costituzioni dei Paesi dell'Unione Europea, Coletânea organizada por EJISABETTA PALICI DI SUNI PRAT e outros, Pádua, CEDAM, 1998, p. 260. 
Foi, assim, por mutação constitucional, antes que por reforma explícita de texto, que a mesma Constituição dos Estados Unidos da América que agasalhou a escravidão, depois a proscreveu; que a mesma Carta que serviu à economia liberal, posteriormente convalidou as intervenções do New Deal; e, para ser breve nos exemplos, lembrando agora um fenômeno de mais amplo espectro, foi por mutação constitucional que as Constituições européias e latino-americanas atuais, que até há pouco tempo se cingiam ao férreo dogmatismo da tripartição de poderes do Estado, passaram a aceitar a pluralidade de centros de poder independentes, como os Bancos Centrais, as Cortes de Contas, os Ombudsmen, os Ministérios Públicos, as entidades dotadas de auto-regulação, ainda que limitada etc., em lista que tende a se ampliar na conformação pós-moderna de um Estado Policêntrico (expressões usadas por MASSIMO SEVERO GIANNINI e por JACQUES CHEVALIER), e, por isso mesmo, cada vez mais Policrático.

A classificação constitucional tradicional que distingue as formas rígidas das flexiveis a partir da existência de cláusulas imutáveis, materiais ou formais, também denominadas cláusulas pétreas (embora para alguns autores ainda subsista com alguma utilidade ou lhes pareça que já "carece de valor prático e teórico em nossos dias" "1), não considerava a natureza e a eficácia próprias de cada categoria de norma constitucional: a norma princípio e a norma preceito (ou regra). Hoje, este é, pois, o critério cientificamente mais relevante.

Com efeito, essa nova distinção passou a ser importante para compreender o fenômeno da mutação constitucional, pois essa variação de interpretação que a caracteriza, recairá sempre sobre a norma preceito, já que uma norma princípio, qualquer que seja, por sua própria essência, está sempre a comportar uma infinita pluralidade de acepções no confronto ponderado com as demais congêneres.

Assim, princípios, como o da livre concorrência e do livre mercado, para citar dois dos mais relevantes no tema sobre o qual se discorre, poderão ser aplicados diferentemente, segundo as distintas situações fáticas que se apresentem aos juízes, sem que isso, todavia, constitua mutação constitucional.

Distintamente, preceitos, para ficar no exemplo econômico, que instituam específicas modalidades de intervenção ou de tributo, não admitirão uma releitura constitucional que expresse uma mutação por via interpretativa.

Da conjugação das duas classificações, a antiga e a nova, encontraríamos uma tipologia teoricamente bastante rica:

1. Constituições rígidas predominantemente preceituais;

2. Constituições rígidas predominantemente principiológicas;

3. Constituições flexíveis predominantemente preceituais; $e$

4. Constituições flexíveis predominantemente principiológicas.

11 MIGUEL ACOSTA ROMERO, Las Mutaciones de los Estados en la Última Década del Siglo XX, México, DF, Ed Porrúa, 1993, p. 4. 
Parece evidente que o quarto modelo, que pode ter como adequado exemplo a Constituição alemã de 1949, é o que abra as mais amplas possibilidades para a alternância democrática de partidos, de homens e de idéias no Poder e, em consequêencia, para adotar políticas econômicas governamentais dentro de um amplo espectro doutrinário.

Com efeito, sempre considerando a notável barreira principiológica do art. 19 (2) ${ }^{12}$ da Lei Básica de Bonn, aquela Carta tedesca comporta confortavelmente uma ampla discricionariedade política no que toca à atuação do Estado na economia, desde que respeitados os princípios balizadores da economia de mercado e de sua orientação social, de modo que a alternância no poder pode ser acompanhada com variações de ênfase ou de intensidade interventiva, o que vem, a ser uma prática que se tem reiterado na rica vivência constitucional daquele País, da qual se têm extraído tantos ensinamentos.

No extremo oposto, como um eloqüente exemplo contemporâneo de modelo rígido e preceitual, a Constituição portuguesa de 1976, em sua versão original, é extremamente limitativa, com barreiras substantivas opostas às revisões de cunho econômico, nasceu problemática, em uma era de constantes e profundas mudanças, como a que se atravessa. No caso de Portugal, foi necessário desatar o nó górdio da combinação da rigidez com a preceituação casuística de sua Carta (art. 288) através do artifício político da chamada dupla revisão: numa primeira reforma geral, aboliram-se certas clausulas pétreas impeditivas da modernização da Carta e, na revisão seguinte, sem esses impedimentos, dispôs-se de maneira condizente com o mainstream dos países da Comunidade Européia e como preparação de seu ingresso.

São as mudanças constitucionais que mantém uma Constituição viva (aggiornamento), ora pela alteração do texto - papel político dos legisladores, que se executa pelas emendas (específicas) ou pelas revisões (gerais) revisão, ora pela variação de interpretação sem alteração do texto - papel dos juízes constitucionais, que a atualizam em seu entendimento (mutação constitucional).

\section{VII - O problema da constitucionalização das mudanças no Brasil}

Em 1988, o constituinte brasileiro não fez, como se esperava, uma opção pelo modelo flexível predominantemente principiológico de constituição econômica, inspirada no protótipo alemão, com suas características de flexibilidade histórica e de adaptabilidade democrática, como, de resto, veio a ser o seguido na maioria dos países que perfizeram suas reformas constitucionais ou promulgavam novas Constituições na linha pós-moderna, em "uma era de grandes câmbios transcendentais", como observou PAUL KENNEDY ${ }^{13}$, vivida entre 1987 e 1992, coincidente, portanto, com a promulgação daquela Carta.

12 "Art. 19 (2) - Em caso algum um direito fundamental pode ser lesado em seu conteudo essencial".

13 PAUL KENNEDY, Auge y caida de las grandes potencias, Barcelona, Plaza y Janes Editores, S.A., 1989, ps 596 a 626, apud MIGUEL ACOSTA ROMERO, op. cit., p.1. 
Ao revés, e não sem estranheza para qualquer observador externo, atento e informado de então, o legislador constitucional preferiu se aproximar do modelo português original antípoda de constituição econômica, ou seja, rígido e predominantemente preceitual, adotando, até mesmo, alguma de suas características que vinham eivadas de preconceito e inadaptabilidade ideológicos conformativos de uma "constituição-programa", tal como qualificada por JORGE MIRANDA. ${ }^{14}$

Em razão dessa estranheza, em obra publicada logo no ano seguinte à promulgação da Carta de $1988^{15}$, tive oportunidade de apontar algumas características anacrônicas da nova Carta no campo econômico, que tendiam a manter certas instituições do Estado moderno, já em plena obsolência, ignorando "os grandes câmbios transcendentais", então em curso. Expunha, então, como embasamento teórico da crítica que oferecia, que:

"Entre um sistema (econômico) real que se apresente distorcido e insuportavelmente injusto, e um sistema ideal utópico e irrealizável, deve-se buscar a construção de um sistema de compromisso flexível que corrija as disfunções mais graves, sem impedir o paulatino e espontâneo aperfeiçoamento organizacional."

"Este sistema possível, simultaneamente oposto ao real e ao ideal e, ao mesmo tempo, conciliador de ambos (ponderado), deverá estar informado por uma sábia combinação de princípios de ordem espontâneos e do necessário influxo de princípios de ordem (racional) introduzidos pela ação do Estado."16

Ora, se, de um lado, os princípios da ordem econômica espontânea das sociedades humanas sequer precisariam ser explicitados, por serem conaturais ao próprio conceito fundante da dignidade da pessoa humana, de outro, todos aqueles que sejam artificialmente introduzidos por construção da razão devem estar necessariamente expressos na Constituição.

A partir daí, tudo passa pelo processo de realização cultural e polifacética da tensão dialética entre os postulados da liberdade (espontâneo) e da igualdade (racional), pois:

"A liberdade é um anseio sempre presente e de permanente conquista histórica da ordem espontânea e, por isso, também muito antiga, mas sua conquista depende, muito mais, de um esforço corretivo racionalmente

14 JORGE MIRANDA, Introdução sobre a Constituição Portuguesa, in Le Costituzioni dei Paesi dell'Unione Europea, Coletânea organizada por ELISABETTA PALICI DI SUNI PRAT e outros, Pádua, CEDAM, 1998, p. 553.

15 DIOGO DE FIGUEIREDO MOREIRA NETO, Ordem econômica e desenvolvimento na Constituição de 1988. Rio de Janeiro, APEC, 1989.

16 Op. cit., p. 26. 
imposto que da evolução natural das sociedades, uma vez que a igualdade não é um imperativo da natureza, mas da justiça."

“Esses princípios, derivados do postulado liberdade, são as chamadas liberdades individuais que, na ordem econômica e social podem resumir-se no seguinte elenco: liberdade de iniciativa, de empresa, de lucro, de competição, de contratação $e$ de apropriação." 17

Tais princípios, vale observar, não reclamam outorga estatal, nem mesmo explicitação constitucional, mas devem ser temperados por correspondentes princípios expressos corretivos de distorções para possibilitar a realização do postulado racional da igualdade.

Assim:

"O principio da livre iniciativa tempera-se pelo da iniciativa suplementar do Estado; o princípio da liberdade de empresa corrige-se como da definição da função social da empresa; o princípio da liberdade de lucro, bem como $o$ da liberdade competição, moderam-se com o da repressão do poder econômico;o princípio da liberdade de contratação limita-se pela aplicação dos princípios de valorização do trabalho $e$ da harmonia e solidariedade entre as categorias sociais de produção; $e$, finalmente, o princípio da propriedade privada, restringe-se pelo princípio da função social da propriedade." 18

Eis a razão pela qual os princípios corretivos devem ter assento expresso nas Constituições: porque qualquer alteração coercitiva da ordem espontânea só se pode legitimar por uma ação constitucionalmente vinculada do Estado. Partiram, pois, dessas premissas teóricas, as críticas ao texto original no campo econômico, então expostas, que desde logo sobressaíam como uma relutância anacrônica, de viés ideológico, em abandonar um modelo de Estado obsoleto que nos relegava à margem da História. ${ }^{19}$

Em pouco tempo essas críticas se mostraram fundadas e a evolução política brasileira mostrou que eram pertinentes e acertadas, pois, com efeito, logo o constituinte reformador reconheceu, em sucessivas emendas constitucionais votadas no ano de 1995, a necessidade de eliminar esses apontados e inúmeros outros gargalos postos pelo constituinte originário ao desenvolvimento econômico nacional.

17 Op. cit., p. 27.

18 Op. cit., p. 28.

19 Op. cit., p. 54. Essa asserção foi abordada in genere e recebeu abundante exemplificação nas páginas 89 a 91 , com referência ao estímulo à ociosidade, ao desestímulo à competição, ao estatismo cartorial, ao estatismo interventivo inconsequiente, ao estatismo burocrata-paternalista, ao controle acionário do Estado, ao estatismo tecnocrato-xenófobo e a um demagógico e irresponsável distributivismo sem produção, tudo com indicação dos respectivos dispositivos criticados. 
Infelizmente, não tão prontamente como seria de se esperar, pois a efetiva correção desses rumos completamente desgarrados das tendências em voga, tal como se apresentavam no panorama econômico global, necessitou da edição de quatro emendas constitucionais específicas para o campo econômico, que só vieram a ser promulgadas depois de demorados e exaustivos processos políticos, custando ao País preciosos sete anos de atraso em sua modernização e na tão anelada retomada do dinamismo econômico, pois que, como se sabe, as mudanças na ordem jurídica dessa natureza, sempre necessitam de um tempo de maturação para produzir efeitos sensíveis. ${ }^{20}$

Não obstante, as mudanças na ordem jurídica em nível infraconstitucional têm prosseguido, ora correndo o risco jurídico da declaração de inconstitucionalidade, ora correndo o risco político de, embora constitucionais, não serem adequadas ou suficientes para os efeitos econômicos desejados.

Por isso, o problema da constitucionalização das mudanças no Brasil deve ser apreciado amplamente sob o prisma juspolítico. Há, por certo, o problema político — da inércia acomodada à que se alia a persistência de preconceitos ideológicos, conspirando para manter preceitos obsoletos quando não prejudiciais aos interesses do País, como ocorre, exemplificativamente, com o velho modelo trabalhista, ainda inspirado na Carta Del Lavoro fascista. Por outro lado, há o problema jurídico do modelo de Constituição extensa, analítica, exageradamente preceitual, casuística e detalhista, que acaba fossilizando inúmeros preceitos cujos conteúdos, não obstante, não deveriam passar de decisões políticas governamentais e vazadas não mais que em leis ordinárias ou, eventualmente, complementares.

Destarte, como a solução não pode ser exclusivamente política, a ser tomada com grande custo e por vezes de forma incompleta, nem, tampouco, exclusivamente jurídica, sempre a depender de eventual maioria em tribunal, que se disponha a adotar uma superação interpretativa satisfatória, conclui-se que o ideal é que ela deva ser preferentemente juspolítica, ou seja: uma revisão constitucional, com especial atenção no aggiornamento institucional da Constituição econômica brasileira, nela necessariamente compreendido o seu caótico e injusto sistema tributário.

\section{VIII - Outras tendências em curso e conclusões}

Estas apreciações não estariam completas sem que se oferecesse uma análise crítica de algumas outras tendências em curso, que também modificam, como efetivamente já o estão, o papel do Estado na economia. Assim, com cautela, para que não se dilargue demasiadamente o campo dessa digressão, seguem-se reflexões sobre alguns temas de ponta, como; (1) a reavaliação do Welfare State e sua possivel transformação em Workfare State; (2) a societização da moeda; (3) a intervenção

20 Foram as Emendas Constitucionais $n^{\circ} \mathrm{s} 6,7,8 \mathrm{e}, 9$, todas do ano de 1995, que modernizaram sucessivamente os setores empresarial, mineral, de transportes, de telecomunicações e radiodifusão e do petróleo. 
econômica através das finanças públicas e (4) a reapreciação das relações contratuais entre os setores público e privado.

1. A reavaliação do Welfare State e sua transformação em Workfare State surgem como um reflexo da inversão de prioridades: a subordinação da política social às exigências do crescimento econômico, e não o revés, já que requer um mercado de trabalho flexível e competitivo, para ser possivel enfrentar, por sua vez, a cada vez mais acirrada competição dos mercados globais. ${ }^{21}$ Em outros termos: ensaia-se, com isso, a transição de um modelo de Estado predominantemente assistencialista para um modelo de Estado predominantemente trabalhista.

2. A societização da moeda, bem como do câmbio e do crédito, parte de conceito liberal da riqueza, como sendo produto da sociedade e não do Estado, pois são os bens e serviços por ela gerados que lastreiam o valor monetário. Assim, o Estado não tem domínio patrimonial originário sobre a moeda e dela não se apropria, senão que meramente a gere em benefício da sociedade, não podendo abusar desse cometimento administrativo nem exercê-lo em desconformidade com as regras científicas aplicáveis.

Esta concepção se instrumentaliza institucionalmente pela separação da administração política, que se vale da discricionariedade administrativa pura e que remanesce com os órgãos de direção puramente político-partidários, da administração técnica, que se vale predominantemente da discricionariedade técnica e, que, por este motivo, se comete a órgãos dotados de autonomia funcional e de independência constitucional (Bancos Centrais), evitando assim uma indesejável politização das decisões de gestão monetária, creditícia e cambiária.

A adoção dessa descentralização através de Bancos Centrais independentes é hoje uma tendência mundial que, ao revés do que se poderia pensar, em vez de debilitar o comando gestor estatal sobre a moeda, torna-o um órgão ainda mais poderoso no sistema reticular de poder do Estado policrático pós-moderno, não só por ser mais consistente com o modelo de mercado aberto e dinâmico em que deve atuar, como por ser substantivamente mais democrático, e não apenas pela sempre estimulada participação da sociedade, como pela eficiência, administrativa proporcionada, e, por tudo isso, muito mais integrado e responsivo aos processos econômicos de cada país (ou comunidades de países, no caso a Européia, como primeiro exemplo de Banco Central Comunitário) onde quer que venham a ser instituídos.

3. A intervenção econômica estatal através das finanças públicas é tałvez o mais importante fenômeno da economia política trazido pela pós-modernidade, não obstante os compêndios de Direito Administrativo da Economia não the terem creditado ainda o devido destaque. Para apreciar a importância dessa atividade estatal em expansão, basta recordar que, no início do século $\mathrm{XX}$, a despesa pública dos países não passava de meros $10 \%$ do produto interno bruto (e, no caso do Brasil, ainda menos) tendo, a partir de então, crescido a um ritmo forte e sustentado, muito

21 B. JESSOP, Comparative Welfare Systems: the Scandinavian Model in a Period of Change, N. York, Saint Martin Press, 1996, apud JACQUES CHEVALIER, op.cit., p. 62. 
superior aos das tradicionais formas interventivas na economia, para alcançar $30 \%$, $40 \%$ e até inimagináveis $50 \%$ do PIB.

$O$ resultado dessa concentração foi o cometimento ao Estado de um formidável poder de alocação de riquezas, que tanto pode ser a distribuição de riquezas, na maior parte das vezes altamente favorável para a economia de um país, quando bem executada, como, ao revés, pode ser a concentração de riquezas, neste caso, sempre desigualadora e indesejável. Essa nova forma de intervenção, que poderia ser chamada de alocativa, que se deriva do manejo de finanças públicas, vem adequadamente apresentada apreciada por SABINO CASSESE (que também nos oferece à meditação os impressionantes números acima referidos) na seguinte passagem de recente obra de sua lavra:

"O recolhimento de recursos por parte dos poderes públicos, serve à distribuição de serviços (produzir bens públicos, na linguagem dos economistas), além de fins de estabilização. Mas, porque não há simetria entre os que contribuem para o recolhimento e os que fruem dos serviços, os poderes públicos terminam, através do fisco e da despesa, por exercer uma função que se pode definir como distributiva ou alocativa." 22

Como se pode observar, essa tendência não apenas atua alocando recursos internamente, para os diversos entes, órgãos e funções do aparelho de Estado em seu conjunto, o que já representa um imenso poder de comando econômico concentrado em órgãos políticos, como atua alocando recursos externamente, para os diversos setores beneficiários da sociedade.

É verdade que as Constituições contemporâneas têm estabelecido quotas de alocação orçamentária obrigatória para certos setores prioritários ou segmentos específicos da sociedade, como, por exemplo, o faz o art. 212 da Constituição de 1988, que determina a aplicação de percentuais mínimos da receita de impostos para a manutenção de desenvolvimento do ensino. Mas, se é certo que tais regras reduzem a discrição política na feitura dos orçamentos, também é certo que elas em nada garantem qualquer correspondência entre os dispêndios compulsórios e uma desejável eficiência administrativa, como seria, na hipótese do exemplo invocada, a qualidade do ensino.

$\mathrm{E}$, como quarto tema de ponta relevante para as relações econômicas entre Estado e sociedade:

4. A recipreciação das relações contratuais de natureza econômica entre o Poder Público e os particulares é a quarta e última tendência em curso a ser aqui lembrada, também apresenta uma forte relação tanto com a ampliação do espaço de atuação econômica do Estado como com a eficiência da ação administrativa (esta hoje elevada a princípio, no art. 37 da Constituição de 1988), envolvendo novos setores de atuação compartilhada, como, por exemplo, o das parcerias público-privadas. Trata-se de uma salutar tendência, observada nos países que se regem por um 
Direito Administrativo, para atenuar os bicentenários privilégios do Estado nas relações contratuais travadas com os particulares e assim aumentar a equidade e a credibilidade nas relações contratuais.

Embora de há muito se saiba que o próprio conceito derrogatório, da igualdade contratual do Direito Privado, próprio do Direito Administrativo, pelo fato de desequilibrar os direitos das partes contratantes, afastasse os interessados das contratações com Estado e acabasse por encarecer as prestações de bens e de serviços de que necessita, ainda assim manteve-se a tradição, que remontava à sua origem bicentenária.

Assim, enquanto perdurou a visão moderna de Estado, de que tais prerrogativas, como necessários reflexos de uma concepção por tantos anos dominantes da supremacia do dictum estatal do interesse público, eram indispensáveis para protegê-lo dos riscos da contratação privada, aceitavam-se acriticamente essas ineficiências, considerando-se justificados tanto a redução do universo dos possíveis contratantes como, e em consequiência, o agravamento dos custos dos bens e serviços adquiridos pela Administração. Hoje, o que passa a ser indispensável é a confiança recíproca, que deve lastrear solidamente os contratos públicos, tanto quanto os privados, e que não se compadece com prerrogativas e privilégios que não sejam os absolutamente indispensáveis para o enfrentamento situações excepcionais, de extrema necessidade e sempre em atos devidamente motivados, previamente ouvidos os interessados.

São essas preocupações que se vem tornando cada vez mais intensas, na medida em que se multiplicam os campos nos quais essa intensificação da contratação entre Estado e particulares se apresenta como a solução áurea para a instituição de parcerias voltadas a equipar a infra-estrutura dos países, notadamente naqueles mais carentes de investimentos, como os que estão em vias de desenvolvimento, que é exatamente o momento em que vive o Brasil.

Ora, a visão pós-moderna alterou duas premissas dessa relação, pondo de manifesto a inconveniência, quando não a inutilidade e o absurdo de manter-se uma fieira das chamadas cláusulas exorbitantes nos contratos desse gênero, e tais são: uma premissa juspolítica - o conceito de Estado Democrático de Direito, e uma premissa jusadministrativa - o princípio da eficiência.

Desde logo, a relação entre o Estado e a sociedade pós-modernos perde a vetusta conotação tutelar, como se existisse uma situação de supremacia do Estado frente a súditos, enquanto, na verdade, invertem-se os valores, pois são os cidadãos, e não mais súditos, que instituem, dirigem e tutelam o Estado.

Esta nova concepção relacional de natureza juspolítica, sobremodo afirmativa dos valores fundamentais da pessoa humana no Estado Democrático de Direito, expressado no art. $1^{\circ}$ da Constituição de 1988 , por si só, vem impondo uma revisão dos resquícios de sujeição que persistem nos contratos administrativos, não obstante a própria idéia de contrato invoque o equilíbrio que deve haver entre as partes.

Mas não apenas por esse motivo, pois outro, até de índole mais prática, concorre para que a atual evolução do Direito Administrativo se caracterize pela intenção de buscar esse reequilíbrio, e que vem a ser, ademais, um motivo especificamente jusadministrativo: o princípio da eficiência, expresso no art. 37 da Constituição de 1988. 
Com efeito, como seria possível conciliar o dever de eficiência imposto à Administração com a rarefação de licitantes de bens e serviços e com a crônica perda para os erários que decorre, em parte, dessa redução do universo de licitantes interessados $\mathrm{e}$, em parte, dos aumentos de preços praticados pelos que acodem às licitações, tidos como compensatórios do risco imposto pela unilateralidade e pela executoriedade das decisões administrativas? Enfim, nessas circunstâncias, como devolver ao setor privado a necessária confiança para relacionar-se contratualmente com o Poder Público, senão revendo o anacrônico rigor de algumas das cláusulas exorbitantes dos contratos administrativos.

Não por outro motivo, juristas contemporâneos se têm interrogado se não é o momento de o Direito Administrativo abandonar a antiquada preocupação com uma afirmação genérica de supremacia de interesses que são cometidos a órgãos do Poder Público que, em tantos casos, não é mais que asserto vago, indiscriminado e tantas vezes equivocado, para "procurar na proteção dos direitos fundamentais uma nova fundamentação para sua instituição". ${ }^{23}$

Ajunte-se a essas premissas, a aguda observação consignada por MARCOS JURUENA VILLELA SOUTO, enfrentando o tema da flexibilização das cláusulas exorbitantes na análise de projetos de lei para a Confederação Nacional da Indústria:

\begin{abstract}
"A presença marcante e intensa do Estado em diversos setores do ordenamento econômico e social sempre causou temor à iniciativa privada, no sentido de verem ocupados seus segmentos de atuação ou de verem exercidas prerrogativas estatais reduzindo direitos, garantias e poupanças privadas.
\end{abstract}

Esse risco tem um custo que ora inviabiliza ora eleva o custo das transações, passando, pois, a ser objeto de preocupações do ordenamento jurídico a contenção do poder estatal como forma de garantir os investimentos que levam ao desenvolvimento econômico." 24

Com essa quádrupla observação sobre tendências que se estão delineando, está-se encerrando esta apresentação e, à guisa de conclusão, em função de todo o exposto, é possivel afirmar que, não obstante o processo de globalização por que passa a economia, e também o fato de que aparelho do Estado vai perdendo sua histórica configuração em pirâmide para adotar o modelo reticular da pós-modernidade, longe de se reduzir sua influência nos processos econômicos, como se poderia imaginar, a vem deslocando do emprego de instrumentos tradicionais de intervenção, que eram característicos do Estado moderno, para atuar com novos meios, muito deles bastante intensos, como alguns que foram examinados neste estudo.

23 J. B. AUBY. La bataille de San Romano. Réflexions sur les évolutions récentes du droit administratif, Actualité juridique-droit administratif, novembre 2001, p. 912 e seg., apud J. CHEVALIER, op. cit., p. 72.

24 MARCOS JURUENA VILLELA SOUTO. Parecer para a CNI, Protocolo 31.157/03, de 22 de setembro de 2003, p. 2. 
Com efeito, uma redução maior de sua influência na economia, que até se poderia ser esperada ao considerar o breve surto de liberalismo econômico que acompanhou o ocaso do Estado moderno, tampouco realmente vem ocorrendo, pois, como se deixou indicado, o peso da carga tributária vem deslocando ponderáveis expressões do Produto Interno Bruto dos países para o manejo da órbita pública, fenômeno este, que faz da atividade orçamentário-financeira do Estado pós-moderno um formidável instrumento interventivo na economia de qualquer país.

Assim é que uma prospectiva mais alentada possivelmente indicará que, em futuro não muito distante, os gigantescos orçamentos públicos serão redimensionados e revistos para paulatinamente espelharem as novíssimas influências da subsidiariedade, da "glocalização", da especialidade, da proximidade e, sobretudo, do avanço das ricas opções da participação cidadã, de modo que é bem provável que uma grande parte dessa gigantesca atividade estatal tenderá a se descentralizar, a desconcentrar decisões, a se realizar em processo aberto e se aproximar dos usuários diretos e, com isso, a se dispor cada vez mais em rede, em tudo o que não exija necessariamente concentração de poder, pois, afinal, esta é a marcha previsível de um novo binômio libertário em ascensão neste começo de século e de milênio: da policracia e da democracia. 


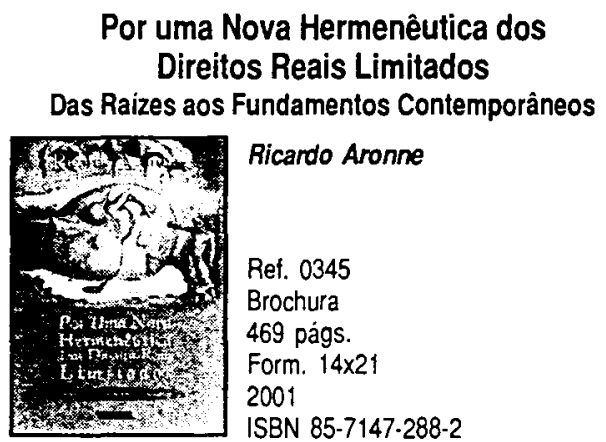

Trata-se de obra oportuna e relevante contribuição para a construção de um direito civil que, afastando-se dos paradigmas do passado, sem aprisionar-se no fetichismo dos conceitos, vem a contribuir para uma transformação dialética do real, com vistas a privilegiar a dignidade da pessoa humana, colocando os bens na condição de instrumentos para esse fim. Um novo modo de se encararem os direitos reais.

\section{Posse:}

Da Segurança Juridica à Questão Social

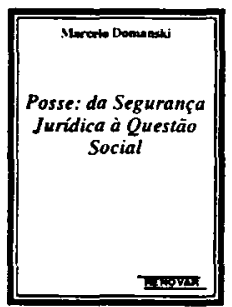

\author{
Marcelo Domanski \\ Ref. 0158 \\ Brochura \\ 354 págs. \\ Form. $13,5 \times 21$ \\ 1998 \\ ISBN 85-7147-070-7
}

Compreende a análise dos múltiplos e complexos aspectos jurídicos e de caráter social que levaram a mudança de orientação sobre a tutela da posse do promitente comprador, antes negada pelo STF, mas posteriormente admitida pelo STJ. 0 autor conjuga à pesquisa jurisprudencial o exame crítico de diversos posicionamentos doutrinários.

\section{Problemas de Direito Civil-Constitucional}

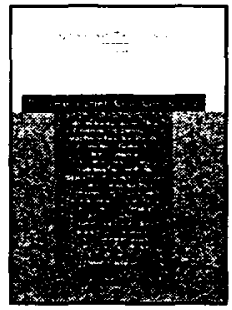

Gustavo Tepedino (coord.)

Ref. 0281

Encadernado

590 págs.

Form. $16 \times 23$

$2001 / 2^{\mathrm{a}}$ ed

ISBN 85-7147-200-9

Fruto do trabaiho realizado pelo grupo institucional de pesquisas denominado Relações Privadas e Sociedade, no âmbito do Programa de Pós-Graduação em Direito Civil da Universidade do Estado do Rio de Janeiro. 0 resultado final reflete os debates e proposições que se estabeleceram entre doutorandos e mestrandos, em torno de quatro temas centrais: relaçōes obrigacionais, de consumo, de propriedade e familiares.

\section{Propriedade e Domínio \\ Reexame Sistemático das Noçōes Nucleares de Direitos Reais}

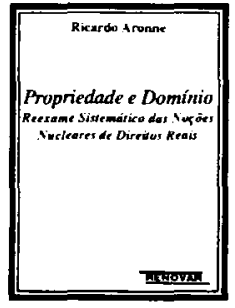

Ricardo Aronne

Ref. 0216

Brochura

230 págs.

Form. $13,5 \times 21$

1999

ISBN 85-7147-124-X

0 autor revisa os conceitos de propriedade e domínio, normalmente examinados a partir de concepções já incompativeis com o sistema jurídico contemporâneo. 0 tio condutor do estudo centra-se na exigência de "repersonalização", que volta o toco do sistema para o individuo inserido no contexto social da sua comunidade, com ênfase nos valores constitucionais que ingressaram no ordenamento modificando o Direito Civil tradicional. 